\title{
Personal Identification using Complete Dentures
}

\author{
${ }^{1}$ Surender Kumar, ${ }^{2}$ Saurav Banerjee, ${ }^{2}$ Hemlata Dwivedi, ${ }^{3}$ Tapas Gupta, ${ }^{4}$ Ardhendu Banerjee \\ ${ }^{1}$ Postgraduate Trainee, Department of Prosthodontics, Dr R Ahmed Dental College and Hospital, Kolkata, West Bengal, India \\ ${ }^{2}$ Postgraduate Student, Department of Prosthetic Dentistry, Dr R Ahmed Dental College and Hospital, Kolkata, West Bengal, India \\ ${ }^{3}$ Professor, Department of Prosthetic Dentistry, Dr R Ahmed Dental College and Hospital, Kolkata, West Bengal, India \\ ${ }^{4}$ Professor and Head, Department of Prosthetic Dentistry, Dr R Ahmed Dental College and Hospital, Kolkata, West Bengal, India
}

Correspondence: Surender Kumar, Postgraduate Trainee, Department of Prosthodontics, Dr R Ahmed Dental College and Hospital, Kolkata, West Bengal, India, e-mail: drsurender_kum@yahoo.co.in

\section{ABSTRACT}

Personal identification is an indispensable requirement for forensic and medicolegal investigations or, in case of an accident, loss of memory, states of unconsciousness being inadvertently misplaced on admission to a hospital or in identifying bodies of those who have died in a calamity. Positive identification through labeled dentures plays a key role in the above-mentioned scenario. The importance of denture identification has long been accredited by the dental profession and various denture identification systems have been reported in the literature. This clinical report highlights a technique of denture identification wherein a used IOPA lead foil with patient details engraved is incorporated within the heat polymerized resin during the processing of the denture.

Keywords: Identification, Forensic, Lead foil.

\section{INTRODUCTION}

Identity of the dead is essential in casualties associated with fire, aircraft accident, explosions and other mass disasters, such as recently struck killer harbor wave-_Tsunami’, earthquakes, and landslides. Without a valid identity, one must consider the ensuing problems of death certification, the disposable of deceased property and the considerable time before the relatives can claim the accrued money on insurance policies or make claim for compensation, where negligence may be involved in traffic accidents. ${ }^{1,2}$

Identification of mutilated remains or decomposed bodies is difficult especially when other parameters (like facial features, scars, tattoos, deformities, peculiarities and personal belongings) fail as in cases of $100 \%$ burns or putrefaction. The teeth and jaws can withstand a great deal of trauma than the rest of the body which can solve the difficulty. The teeth may be as unique as the fingerprints in identification and this aspect of dentistry is called as forensic dentistry. The real problem of identification arises when such patient becomes edentulous and, therefore, the need for denture identification system may resolve their identity problem.

Patients in nursing homes and other health care facilities often misplace their dentures, leading to the problem of identification. ${ }^{3}$ Patients who have lost their memory owing to personal health issues, such as Alzheimer's disease, denture labeling can provide personal identity. Previous attempts have focused on marking methods that have either ruined the denture esthetics or increased the denture weight. Also, the flammable and fragile nature of the denture has rendered them unsuitable for marking system. Various recommendations have been made concerning the importance of denture identification and several methods of the same have been described in literature. ${ }^{4}$ They are broadly divided into surface marking and inclusion methods. The surface marking methods include engraving the cast, scribbling on dentures/writing on the denture surface, while the inclusion methods involve incorporation of microchips, lenticular cards and radio-based tagging transponders into the dentures ${ }^{6,9-11}$

The surface engraving can cause detrimental effects, such as lodgment of food debris resulting in bacterial infection and decrease strength of denture. The surface markers were rapidly removed by one or more abrasive, denture cleansers and antiseptic/mouthwash agents. Studies have revealed that 'embossing' initials on intaglio surface of dentures are associated with malignancies maybe due to constant tissue irritation. ${ }^{7}$ The inclusion methods are more permanent as opposed to the relatively simple surface marking methods; however, these techniques require certain skills, time and equipments not readily available in the dental laboratories. This report describes an easy, inexpensive procedure for incorporating accurate identification marks on dentures using IOPA radiograph lead foils.

\section{CASE REPORT}

A 48-year-old male patient reported to the department with chief complaint of difficulty in chewing food. Medical history was not contributory. Intraoral examination revealed a completely edentulous maxillary and mandibular arch. Patient was a car driver. Treatment plan was to fabricate a complete denture with the identity of the patient for future identification 
in case of any mishap to aid in forensic study. The procedures were as follows:

1. Following try-in, wax-up of the trial dentures, flasking and dewaxing were done (Fig. 1).

2. Separating medium was applied. A small amount of heatcure clear acrylic resin (DPI, Mumbai) was mixed and placed over the posterior lateral region of palate. A wet cellophane sheet was positioned and trial closure was done. This prevented the shifting of the lead foil during the final closure.

3. The flask was reopened, flash trimmed away and cellophane sheet removed.

4. A piece of lead foil from a used IOPA radiographic film $(2.5 \times 0.6 \mathrm{~mm})$ was cut and patient's details (patient's name, outpatient—case number, hospital's name and dentist's name) were engraved with a sharp pointed instrument (Fig. 2). The lead foil was then incorporated posteriorlaterally over the palate of the maxillary denture and over the lingual flange area in the mandibular denture (Figs 3 and 4).

5. Characterization of denture base was performed. Heat-cured pink veined polymethyl methacrylate resin was packed into the flask at dough consistency.

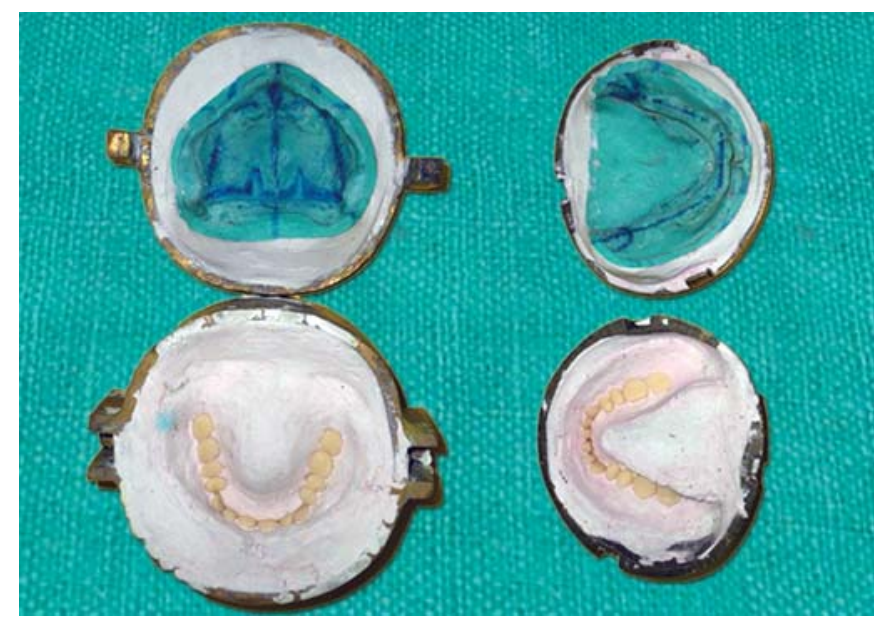

Fig. 1: After complete dewaxing

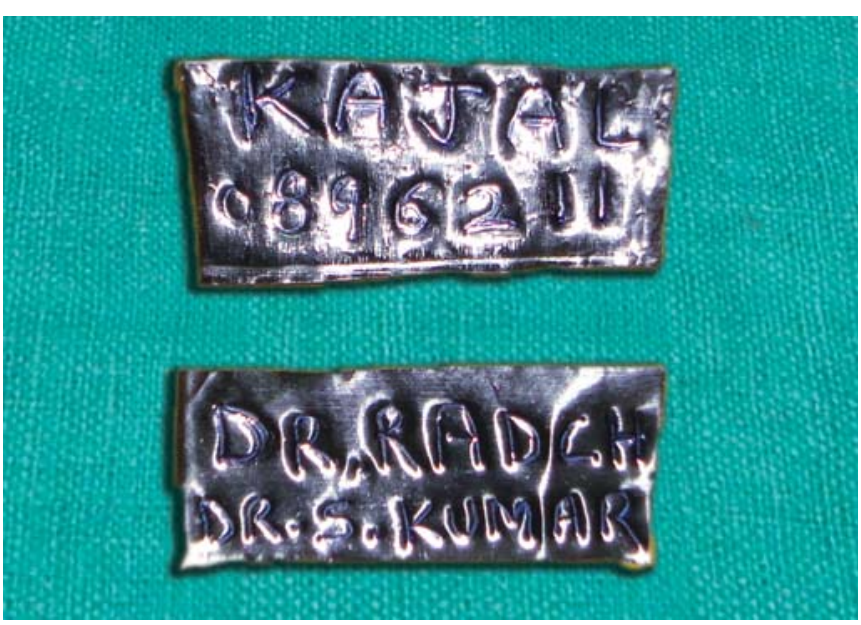

Fig. 2: Label with patient details

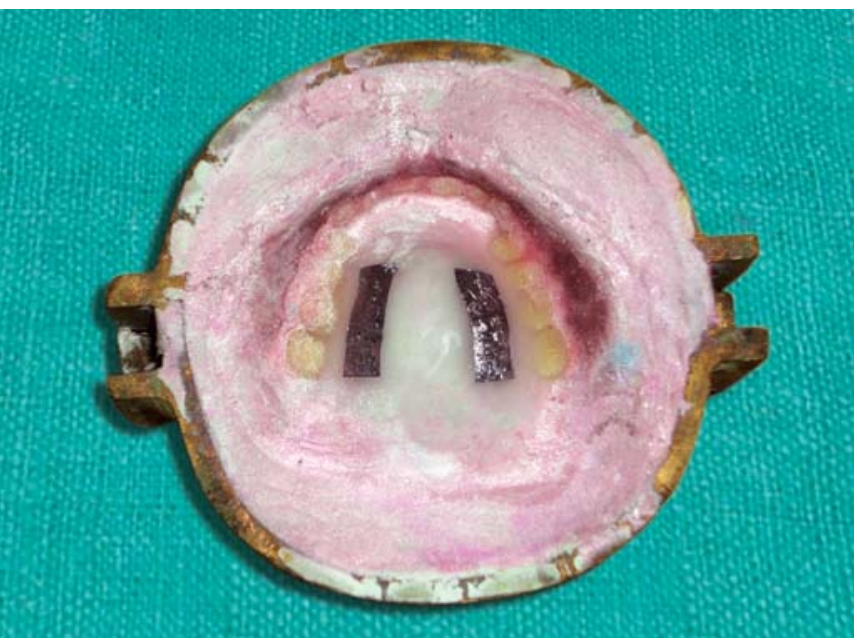

Fig. 3: Positioning of label in posterolateral region of palate

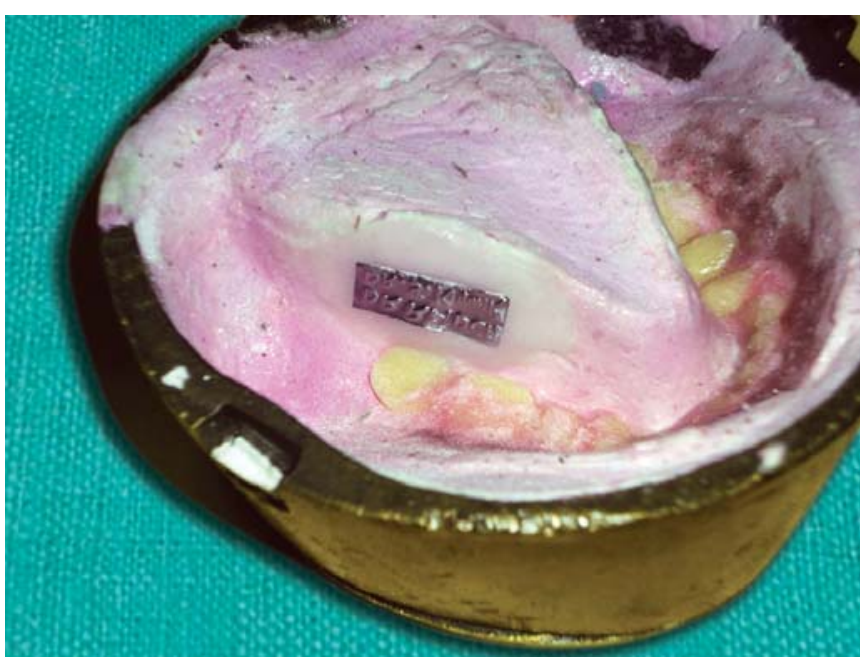

Fig. 4: Positioning of label in the lingual flange

6. After curing and bench curing, the dentures were retrieved.

7. Finishing, polishing and occlusal corrections were done prior to denture delivery (Figs 5 to 7).

8. An intraoral periapical radiograph was taken which revealed the complete details of the patient (Fig. 6).

9. Patient was recalled after 15 days and a month for evaluation and observed no sign of tissue reactions.

\section{DISCUSSION}

It is obvious that only marked dentures can reveal the positive identity of a person when all other methods rendered absolutely dud. The dentist should always inform the patient clearly the benefits of denture labeling and motivate the patient for the same. However, the patient has right to refuse. Some of the procedures for denture labeling may be too expensive or unesthetic for the patient. Because there is international consensus about methods of denture marking, we suggest newer methods for the same.

Five requirements of marking dentures were suggested by Kruger-Monson. They were as follows: 


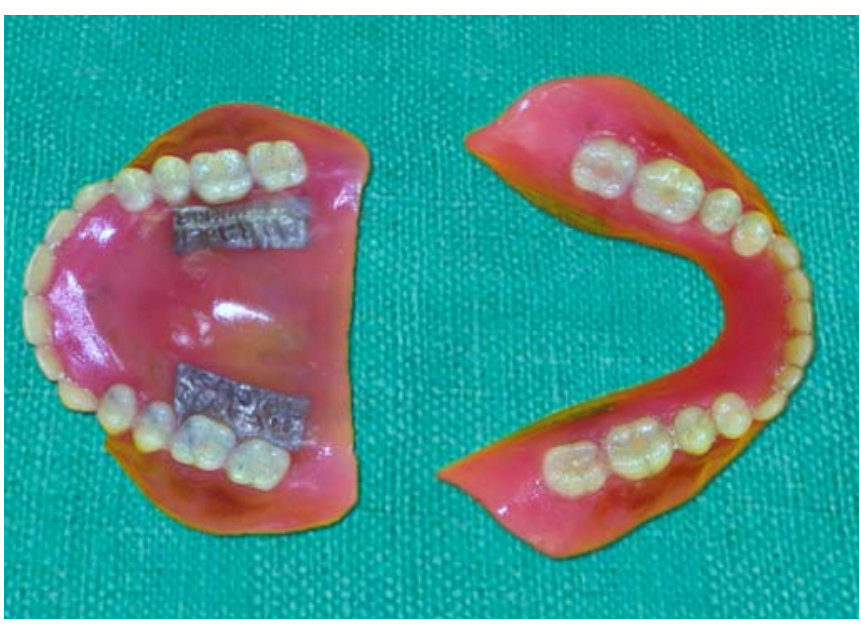

Fig. 5: Postoperative extraoral view of the prosthesis

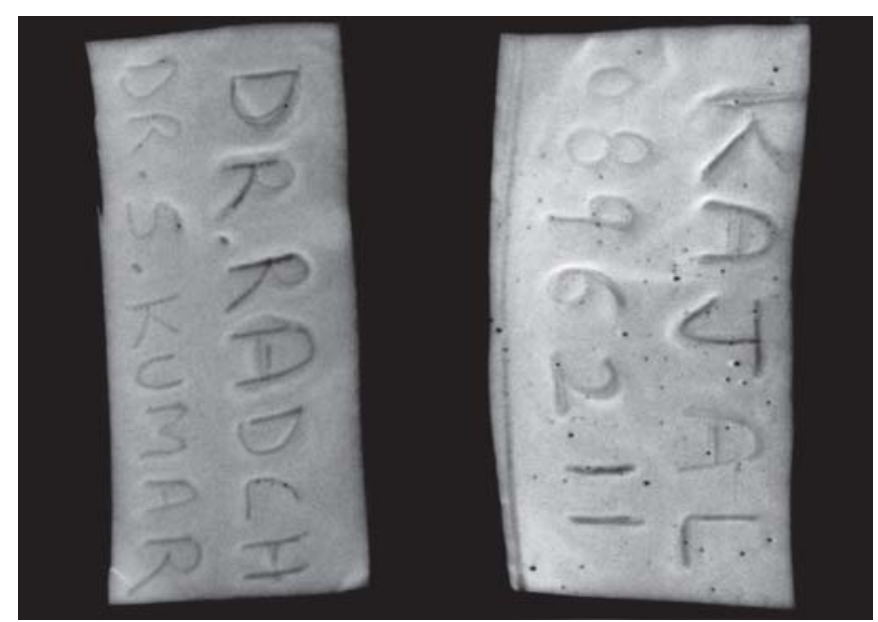

Fig. 6: IOPA radiograph showing patient's details

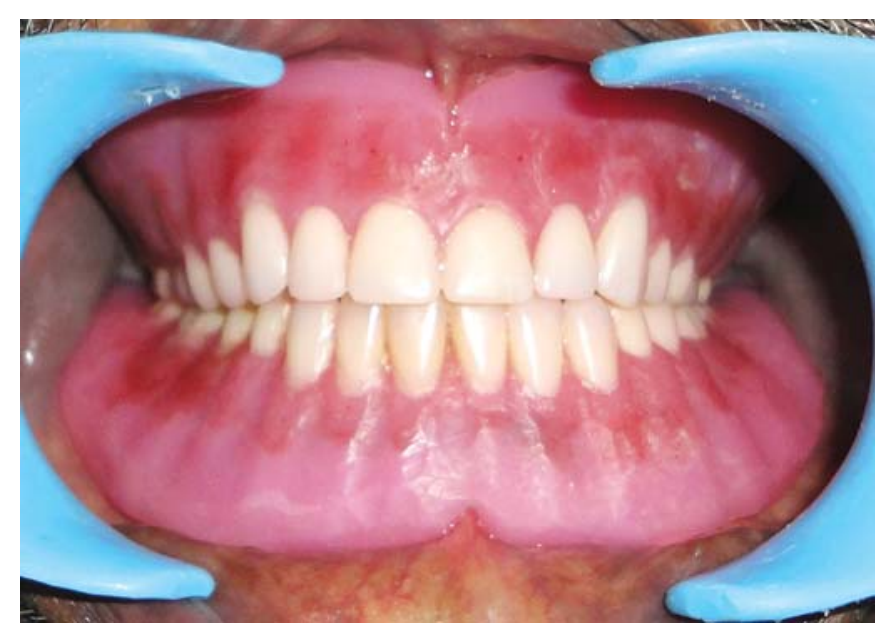

Fig. 7: Postoperative intraoral view of prosthesis

1. The strength of the prosthesis must not be jeopardized.

2. It must be easy and inexpensive to achieve.

3. The identification system must be efficient.

4. The marking must be durable and visible.

5. The marking must withstand fire and humidity.

In addition, radiopacity of the identification label should be among this list. ${ }^{5}$
One of the current denture marking methods is lenticular system. It can store larger amount of information making effective use of space. Special glasses or devices are not required for data interpretation. Incorporation of a lenticular film in denture requires meticulous handling; avoiding surface contact of the lens during finishing and polishing of the denture. It may also be heat sensitive. ${ }^{8}$

Bar code system and microchip permit storage of large amount of information but at cost of high price. Both these systems require a hand-held reader or computer for data interpretation. ${ }^{9}$ Specially, equipped laboratories can provide a copper vapor laser (CVL) that can etch a patient's identification into the metal surface of a partial denture. A CVL can label the cobalt-chromium components of dentures easily, legibly and reduce the font size of the data. However, this method is not only expensive but also requires specialized equipment. With the value of denture markings and gaining better understanding, high-end technology was tried to label dentures. The patient's details were etched onto a chip measuring $5 \times 5 \times 0.6 \mathrm{~mm}$. Tests conducted on chips embedded in acrylic resin performed well under high temperatures $\left(600^{\circ} \mathrm{C}\right)$, had excellent acid resistance, was radiopaque and bonded well with acrylic resin. The main disadvantage of the chip was that it could be inscribed only by the manufacturer and not by the dentist. ${ }^{7}$

The inclusion of radiofrequency identification (RFID) tags within dentures is a cosmetic, effective labeling method permitting rapid and reliable identification of the wearer. They are preferred because of their small size $(8.5 \times 2.2 \mathrm{~mm})$ and high data storage capacity. No special training is required to set the tag in the denture. Unfortunately, RFIDs are not widely used due to their high cost and lack of availability in most dental setups. ${ }^{7,10}$ A new denture marker makes use of the patient's photograph embedded in clear acrylic denture base. This method is mainly useful in countries with low literacy rate, where a photograph is the easiest method of identification. However, thermal tests revealed that the photographic marker and bar code were only resistant to around 200 to $300^{\circ} \mathrm{C}$.

The technique described in this article utilizes used IOPA film foils generally available at dental clinic and laboratory for denture labeling. The radiopaque foil aids in detection of an aspirated temporary partial denture. Since the lead foil is thin, it does not hamper the strength of denture and is heat resistant. Inscribing the details with pen (ink) stained the clear acrylic; therefore engraving of lead foil was performed with a sharp pointed instrument.

\section{CONCLUSION}

This article describes an easy and cost-effective technique with readily available armamentarium in any dental office or institution for denture identification. The label demonstrates no sign of deterioration, withstands high temperature and is esthetic. It is biologically acceptable and fulfils all the forensic requirements of a suitable prosthesis. 


\section{REFERENCES}

1. Fumi Takahashi, Toshiaki Koji, Osami Morita. A new method for denture identification. Dental Materials Journal 2008; 27(2):278-83.

2. Kamath PG, Kamath VG. Engraved fixed restorations and denture micro-labelling to facilitate identification through forensic dentistry. J Prosthodont Society 2005;5:79-81.

3. Todo J, Lukens EM. A technique for placing names in dentures. J Prosthet Dent 1977;37:469.

4. Reeson MG. A simple and inexpensive inclusion technique for denture identification. J Prosthet Dent 2001;86:441-42.

5. MacEntee MI, Campbell T. Personal identification using dental prostheses. J Prosthet Dent 1979;41:377-80.
6. Bansal PK, Sharma A, Bhanot R. Denture labelling: A new approach. Contemp Clin Dent 2011;2:76-78.

7. Datta Pankaj, Sood Sonia. The various methods and benefits of denture labelling. J Forensic Dent Sci Jul-Dec 2010;2(2): 53-58.

8. Colvenkar SS. Lenticular card: A new method for denture identification. Indian J Dent Res 2010;21(1); 12-14.

9. Rajan M, Julian R. A new method for making dentures using microchips. J Forensic Odontostomatol 2002;20:1-5.

10. Millet C, Jeanin C. Incorporation of microchips to facilitate denture identification by radiofrequency tagging. J Prosthet Dent 2004;92:588-90.

11. Milward PJ, Shepherd P, Brickley MR. Automatic identification of dental appliances. Br Dent J 1997;182:171-74. 